\title{
NUMERICAL MODELING TECHNIQUE FOR PREDICTING THE SEISMIC FAULT ZONE (SFZ) IN THE EARTHQUAKES AFFECTED AREA, NW HIMALAYAS WITH ITS NEOTECTONIC IMPLICATION
}

\author{
M. Farhad Howladar ${ }^{1 *}$, Sharmin Afroz ${ }^{1}$ and Shofiqul Islam ${ }^{2}$ \\ ${ }^{1}$ Department of Civil and Environmental Engineering, University of America Bangladesh, Rajshahi Campus, \\ Rajshahi, Bangladesh; ${ }^{2}$ Department of Petroleum and Georesources Engineering, Shah Jalal University of Science \\ and Technology, Sylhet, Bangladesh
}

\begin{abstract}
Finite elements analysis is a powerful tool, often used for analyzing problems on stress, that can be successfully employed to analyze the finite deformation of geological structures in a mathematical form on a digital computer. Over the last century, great earthquakes with magnitudes of 7->8 have struck in the NW Himalaya; the 1905 Kangra earthquake is one of them. This study performed a plane strain analysis of failure stress and faults in these earthquakes potential region based on the seismic geologic cross profile employing the two-dimensional finite element method under elastic material state with Mohr Coulomb failure criterion. The results show that the normal fault initiates at deeper level, whereas with increasing convergent displacement the thrust fault appears in the shallower region. The results of the simulation are compared with the available seismic and earthquakes focal mechanism solution data of the area which shows the close similarities between the distribution of simulated fault and microseismicity in the deeper region of Chamba Nappe $(\mathrm{CN})$ and along the upper part of the Mid Crustal Ramp (MCR) which might be the Seismic Fault Zone (SFZ) of the region. Moreover, the intense localization of faults along the frontal part of the model indicates that this part is active in nature at present, which is responsible for the neotectonics in the Himalayas.
\end{abstract}

Keywords: NW Himalaya, numerical technique, seismic fault zone, neotectonics

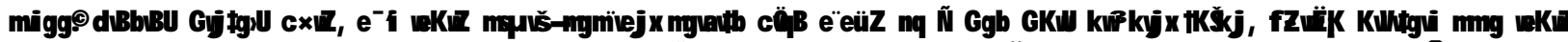
Ue 抽

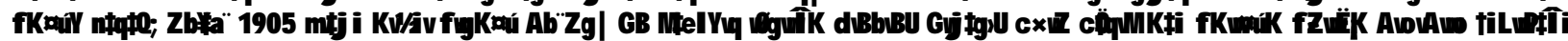

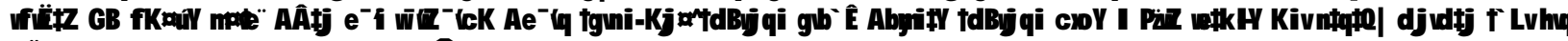

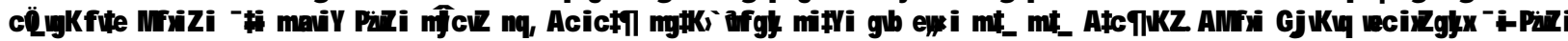

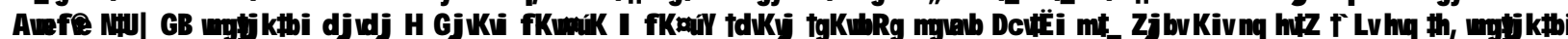

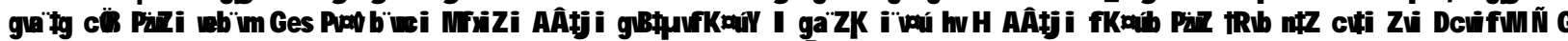

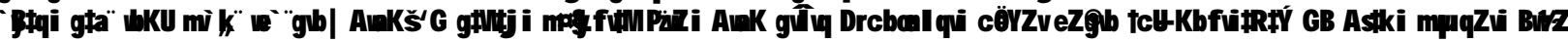
enb K $\ddagger$ humgyj $\ddagger$ i

\section{Introduction}

On a cold afternoon high up in the hills in the north of the Indian subcontinent, a short gaze towards the horizon by the light snowy touch of the day's fading brush strokes will reveal one of nature's most magnificent monuments - the towering Himalayas. Among the most dramatic and visible creations of plate tectonic forces are the lofty Himalayas, which stretch over $2900 \mathrm{~km}$ along the border between India and Tibet. These immense mountain ranges were formed as a result of collision between the Indian and Eurasian plates. From west to east the Himalayas are differentiated broadly into three mountainous regions (DeCelles et al. 2000): the western Himalayas, the central Himalayas and the eastern Himalayas. The Himalayan mountain chain is divided longitudinally by principal thrusts into five tectonic zones (Upreti 1999; Fig. 1 upper), called the sub-Himalaya (SH), the Lesser Himalaya (LH), the Higher Himalaya (HH), the Tethys Himalaya (TH), and the Indus Suture (IS). The principal thrusts are Main

*Corresponding author, Email: dmfh75@yahoo.com
Frontal Thrust (MFT), Main Boundary Thrust (MBT) and Main Central Thrust (MCT). The northward convergence of India keeps the entire Himalayan mountain arc seismically active. The earthquakes occur in two parallel belts in the Himalayan arc (Seeber et al. 1981). Over the last century, the Himalayan arc has experienced four great earthquakes (Fig. 1 upper) with magnitude of $\mathrm{M}>8$ in 1897 (Assam), 1905 (Kangra), 1934 (Bihar) and 1950 (Assam). The earthquakes in the magnitude range of 6 to 7 occur in the northern part of the Lesser Himalaya and beneath the Higher Himalaya (Thakur 2004). Even today, numerous medium to small scale earthquakes keep striking in the Himalayas as well as NW Himalayas (Fig. 1 lower; where also included their possible fault plane solutions). From such features, it is obvious that structures and deformation of the regions are largely influenced by these activities. Therefore it is essential to improve knowledge of the structural characteristics (fault) along the geologic as well as structural cross section in the earthquakes affected regions in the NW Himalayas. 


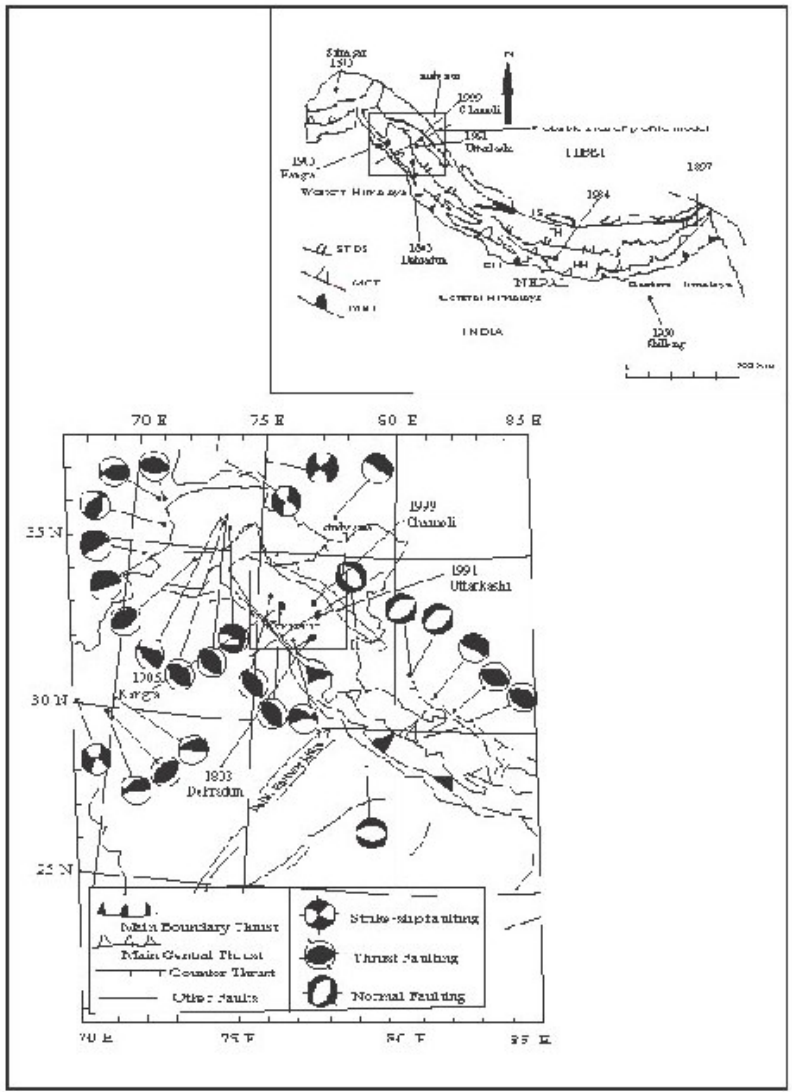

Fig. 1. Upper figure shows the sketch map of the Himalayan arc with the distribution of major earthquakes within it (created after Kaneko 1997 and Thakur 2004). The lower figure shows the major and minor earthquake events with their focal mechanism solution of faults in the NW Himalayas (after Chandra 1978).

The aim of this study was to apply the numerical simulation technique (Finite Element Method) for calculating the failure stress state and faults with an allowance for the rock layer properties and convergent displacement under Mohr Coulomb failure criterion. Then the simulated results are compared with the microseismicity and earthquake focal mechanism solution of faults of the region. Finally combining all of these data, an effort has been made to discuss the seismic fault zone with its neotectonics in the area.

\section{Microseismic characteristics of the Himalayas}

The structure, topography and seismicity are quite uniform along the Himalayan front. The most prominent seismic feature is a narrow earthquakes belt where all available fault-plane solutions indicate thrusting, and this belt can easily be identified along the entire Himalayas (Seeber et al. 1981). Himalayan mountain range and its adjoining area constitute one of the most seismically active regions of the world. Four earthquakes with magnitudes greater than 8 occurred since 1897, and all appear to be related to mountain building processes in the Himalayas. The earthquakes epicenters fall near the trace of the MCT, but not near the MBT. From this observation, it is tempting to conclude that the MCT is active but not the MBT. However, if one considers that the MBT dips gently to the north or northeast (Gansser 1964) and that earthquakes occur at finite depth, it seems more reasonable to conclude that along most of the Himalayas, the activity is associated with the MBT and the zone surrounding it. The seismicity at both ends of the Himalayas appears to be more complicated with diffuse zone south of the main ranges.

The southward migration of thrust faults may result in part from the buoyancy of continental crust. In the east, seismicity is distributed over the Shillong plateau and its margins. Arambruster et al. (1978) and Jacob et al. (1976) considered both the MCT and MBT to be active in the northwest meanwhile the tectonics of this part of the Himalayas is possibly more abstruse than in the southeast. From these pictures the above authors assumed that the seismicity along the entire range is not restricted to a single narrow fault zone. The level of seismic activity along the Indus-Tsangpo suture zone is very low. The lack of seismicity along the suture zone indicates that this region is relatively rigid, it does not keep stress and transmit them to the neighboring regions.

\section{Method of numerical modeling}

In order to define the method, we primarily followed Zienkiewicz and Cheung (1967). In the present analysis, the finite element method is used to determine the stress and strain in 2D elastic structures of simple geometry with constituent material properties of different rock layers. An assemblage of triangular elements is used to represent the continuous structures.

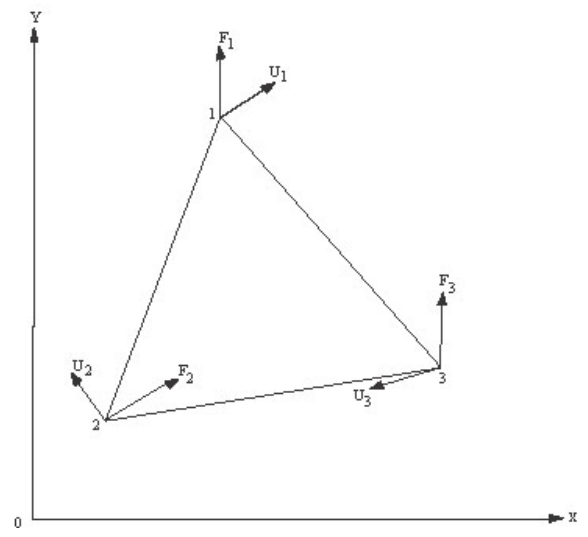


From equation (4) the generalized displacement vector Modeling technique for predicting earthquakes

For a typical element (Fig. 2), assuming homogeneous stress within the element, the vector of nodal displacements $\mathbf{u}^{\mathbf{e}}$ and the vector of nodal forces $\mathbf{F}^{\mathbf{e}}$ can be express in matrix form as:

$\mathbf{u}^{\mathbf{e}}=\left\{\begin{array}{l}u_{1} \\ u_{2} \\ u_{3}\end{array}\right\}=\left\{\begin{array}{l}u_{1 x} \\ u_{1 y} \\ u_{2 x} \\ u_{2 y} \\ u_{3 x} \\ u_{3 y}\end{array}\right\}, \mathbf{F}^{\mathbf{e}}=\left\{\begin{array}{l}F_{1} \\ F_{2} \\ F_{3}\end{array}\right\}=\left\{\begin{array}{l}F_{1 x} \\ F_{1 y} \\ F_{2 x} \\ F_{2 y} \\ F_{3 x} \\ F_{3 y}\end{array}\right\} \ldots \ldots \ldots . . .(1)$

By continuity of displacement within the element and with adjacent elements, a displacement function of two linear polynomials can be chosen for the case of two dimensions. Hence, it can be represented as follows:

$\mathbf{U}=\left\{\begin{array}{l}u_{x} \\ u_{y}\end{array}\right\}=\left[\begin{array}{lll}a_{0} & a_{1} & a_{2} \\ b_{0} & b_{1} & b_{2}\end{array}\right]\left\{\begin{array}{l}1 \\ x \\ y\end{array}\right\}$.

Where, $\mathrm{U}$ is the inner displacement vector. Equation (2) may be written in the form as:

$\mathbf{U}=\left[\begin{array}{cccccc}1 & x & y & 0 & 0 & 0 \\ 0 & 0 & 0 & 1 & x & y\end{array}\right] \cdot\left\{\begin{array}{l}a_{0} \\ a_{1} \\ a_{2} \\ b_{0} \\ b_{1} \\ b_{2}\end{array}\right\}=\left[R^{\prime}\right] \alpha \ldots$

Therefore the vector of nodal displacement is listed as a product of matrix and vector:

$\mathbf{u}^{\mathbf{e}}=\left\{\begin{array}{l}R_{1} \\ R_{2} \\ R_{3}\end{array}\right\} \cdot \alpha=[R] \cdot \alpha$

Where $[\mathrm{R}]$ is the shape function matrix and $\alpha$ is the generalized displacement vector. Using $\mathrm{x}_{\mathrm{i}}$ and $\mathrm{y}_{\mathrm{i}}$ for the $\mathrm{x}$ - and $\mathrm{y}$ - coordinate at the nodal point $\mathrm{i}$, the shape function matrix $\left[\mathrm{R}_{\mathrm{i}}\right]$ at the point is represented by:

$\left[R_{i}\right]=\left[\begin{array}{cccccc}1 & x_{1} & y_{1} & 0 & 0 & 0 \\ 0 & 0 & 0 & 1 & x_{1} & y_{1}\end{array}\right](i=1,2,3) \ldots$
Using $\Delta$ for $\operatorname{det}\left[\begin{array}{lll}1 & x_{1} & y_{1} \\ 1 & x_{2} & y_{2} \\ 1 & x_{3} & y_{3}\end{array}\right]$, the inverse matrix $[R]^{-1}$ will be expressed as:

$$
[R]^{-1}=\frac{1}{\Delta}\left|\begin{array}{llllll}
\Delta_{11} & 0 & \Delta_{21} & 0 & \Delta_{31} & 0 \\
\Delta_{12} & 0 & \Delta_{22} & 0 & \Delta_{32} & 0
\end{array}\right|
$$

where $\Delta$ equals two times the area of the triangle elements and $\Delta_{i j}$ is the cofactor of $\mathrm{i}, \mathrm{j}$-components of $\Delta$; for example, $\Delta_{23}=-\operatorname{det}\left[\begin{array}{ll}1 & x_{1} \\ 1 & x_{3}\end{array}\right]$

Consequently, from equations (3) and (6) the inner displacement of the triangle is equated as follows:

$$
\begin{aligned}
\mathbf{U} & =\left[R^{\prime}\right] \cdot \alpha \\
& =\left[R^{\prime}\right] \cdot[R]^{-1} \cdot \mathbf{u}^{\mathbf{e}}
\end{aligned}
$$

Now strain vector $\mathbf{e}$ is represented as;

$$
\begin{aligned}
& \mathbf{e}=\left\{\begin{array}{l}
\varepsilon_{x} \\
\varepsilon_{y} \\
\tau_{x y}
\end{array}\right\}=\left\{\begin{array}{c}
\frac{\partial u_{x}}{\partial x} \\
\frac{\partial u_{y}}{\partial y} \\
\frac{\partial u_{x}}{\partial y}+\frac{\partial u_{y}}{\partial x}
\end{array}\right\} \\
& \left\lceil\begin{array}{llllll}
0 & 1 & 0 & 0 & 0 & 0
\end{array}\right] \\
& =\left|\begin{array}{llllll}
0 & 0 & 0 & 0 & 0 & 1
\end{array}\right| \cdot \alpha=[B] \cdot \alpha
\end{aligned}
$$$$
=[B] \cdot[R]^{-1} \cdot \mathbf{u}^{\mathbf{e}}
$$

Where the matrix $[B]$ is called the strain-generalized displacement matrix; and its components are not functions of variables $x$ and $y$, so that one can see the strain constant in each element.

The relation of stress vector $\mathrm{p}$ and strain vector $\mathbf{e}$ is:

$\mathbf{P}_{=}\left\{\begin{array}{c}\sigma_{x} \\ \sigma_{y} \\ \tau_{x y}\end{array}\right\}$ 
$E(1-v) \quad\left|\begin{array}{cc}1 \frac{v}{1-v} & 0 \\ v & 1\end{array}\right| \mathbf{e}=[K] \cdot \mathbf{e} \ldots .$.

Howladar et al.

Where, $v$ is the Poisson's ratio, $\mathrm{E}$ is the Young's modulus and $[\mathrm{K}]$ is the stress-strain matrix. Equation (10) is valid for the case of plane strain.

Let the virtual displacement be $U^{* e}$ when the element is deformed, the strain energy $\mathbf{U}$ of this element is given by:

$=\int_{v}\left(e^{*}\right)^{T} \cdot \mathbf{P d V}$

$=\int_{v}\left(e^{*}\right)^{T} \cdot[K] \cdot \mathbf{e d V}$

$=\int_{v}\left(u^{* e}\right)^{T} \cdot\left([R]^{-1}\right)^{T} \cdot[B]^{T} \cdot[K] \cdot[B] \cdot[R]^{-1} \cdot \mathbf{U}^{\mathbf{e}} \mathrm{dV}$

$=\int_{v}\left(U^{* e}\right)^{T} \cdot\left[B^{*}\right]^{T} \cdot[K] \cdot\left[B^{*}\right] \cdot \mathbf{U}^{\mathrm{e}} \mathrm{dV}$

Where, $\left[B^{*}\right]$ is equal to $[B] \cdot[R]^{-1}$ and $e^{*}$ is the vector

of virtual strain. As the nodal forces are already defined by equation (1), the external work $\mathrm{W}$ is:

$\mathrm{W}=\left(\mathbf{U}^{* \mathrm{e}}\right)^{\mathrm{T}} \mathbf{F}^{\mathrm{e}}$

And the strain energy is equal to the external work, therefore the following equation holds:

$$
\begin{gathered}
\left(\mathbf{U}^{* \mathrm{e}}\right)^{\mathrm{T} .} \mathbf{F}^{\mathrm{e}}=\int_{v}\left(u^{* e}\right)^{T} \cdot\left[B^{*}\right]^{T} \cdot[K] \cdot\left[B^{*}\right] \cdot \mathbf{U}^{\mathrm{e}} \mathrm{dV} \\
=\left(\mathbf{U}^{* \mathrm{e}}\right)^{\mathrm{T}} \cdot\left\{\int_{v}\left[B^{*}\right]^{T} \cdot[K] \cdot\left[B^{*}\right] d V\right\} \mathbf{U}^{\mathbf{e}}
\end{gathered}
$$

While the vector of nodal force is represented by:

$\mathbf{F}^{\mathrm{e}}=\left\{{ }_{v}\left[B^{*}\right]^{T} \cdot[K] \cdot\left[B^{*}\right] V\right\} \cdot \mathbf{U}^{\mathrm{e}}$

Now, the stiffness equation is obtained by

$\mathbf{F}^{\mathbf{e}}=[\Lambda] . \mathbf{U}^{\mathbf{e}}$

Where, $[\Lambda]$ is called the stiffness matrix and can be written in the following form:

$$
[\Lambda]=\int_{v}\left[B^{*}\right]^{T} \cdot[K] \cdot\left[B^{*}\right] \mathrm{dV}
$$

In this case, each matrix is constant in the element, hence the product of matrices i.e. $\left[B^{*}\right]^{T} \cdot[K] \cdot\left[B^{*}\right]$ is constant. Consequently, it is possible to take off the integral mark: $[\Lambda]=\left[B^{*}\right]^{T} \cdot[K] \cdot\left[B^{*}\right] \cdot \mathrm{V}$, where $\mathrm{V}$ is the volume of the element.

By solving the above stiffness matrix, one can get undecided nodal forces and nodal displacements for every element. Moreover, using these nodal displacements, the values of stress and strain could be obtained. Further and detailed discussions on FEM are referred to Zienkiewicz and Cheung (1967) and so forth. Noyt faulte are develoned and slaccified from the

respectively.

\section{Presentation of numerical experiments}

How to fit the parameters of model: In order to present the numerical experiment, primarily the geometrical and mechanical parameters are setup carefully while both of them are very influential to the distribution of stress and fault in nature. The aim of this modeling process is to understand the effects of the geometrical and mechanical parameters to stress distribution and fault development in the model. Therefore the geometry of the model (Fig. 3) has been modified and reconstructed from Powers et al. (1998) and Thakur et al. (2000) and the mechanical parameters values used are those giving a reasonable scale, but finally the average value is adopted for the simulation.

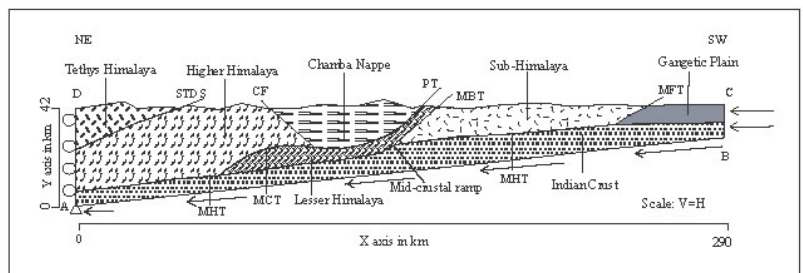

Fig. 3. Simplified geologic profile of NW Himalayas rearranged after Powers et al. (1998) and Thakur et al. (2000) where the geometry and boundary constraints also included considering the present convergent direction of Indian sub-plate. Different layers properties (Young's modulus Poisson's ratio, density, cohesion and angle of internal friction are shown in Fig. 4). Open triangle $=$ fixed point; open circles $=$ fixed only horizontal direction, arrows $=$ imposed displacement. The simplified model consists of seven structural units which are separated by regional thrusts. The structural units are Tethys Himalaya, Higher Himalaya, Lesser Himalaya, Chamba Nappe, SubHimalaya, Gangetic Plain and Continental crust. The thrusts are MCT, PT, CF, MBT, MFT and MHT.

\section{Geometrical parameters}

The initial geometry of the numerical system (length, depth, structures and the dip of the model) is defined according to the cross section across the earthquakes affected area in the NW Himalayas (Powers et al. 1998; Thakur et al. 2000). The cross section is based mainly on the field-work and locally on the seismic reflection profile which shows north to south verging thrusts. The present length of the section model is $290 \mathrm{~km}$ with a maximum width of $42 \mathrm{~km}$ (Fig. 3). According to Powers et al. (1998) and Thakur et al. (2000), the dip of the 
cross section increased gradually from south to north. In the model this dip varies slightly along the basal part of sub-Himalayan sequence. This variation reflects the unexpected effects on the whole model result that is 61

Himalayan Thrust (MHT) and MCR. The sequential spacing of different tectonic divisions from the north to south are: Tethys Himalaya, Higher Himalaya, Chamba Nappe, Lesser Himalaya, Sub-Himalaya, and the Gangetic Plain.

\section{Mechanical parameters}

In spite of these regards, we simplified the model and divided it into different layers and choose major common rocks for each layer to avoid complexity of calculations. The rocks of each layer are characterized by the physical parameters, such as the Young's modulus (E), Poisson's ratio ( $v)$, density $(\rho)$, cohesion (c) and Internal Friction Angle $(\varphi)$. Within the general simplifications of model, the choice of these parameters of rock offers a good approximation. The elastic constants include the $(\mathrm{E})$ and $(v)$. The actual values of these parameters are not well constrained; as a consequence, we tested model with a variety of values in order to explore the effects of changes in parameters and their sensitivity to the results. Five parameters $(\mathrm{E}, v, \rho, \mathrm{C}$ and $\varphi$ ) for each layer are shown in Fig. 4. Because several major structural units have quite different rheological properties. The abundance of these parameters of rock in each layers is also shown in Fig. 4. The highest values of all mechanical properties are taken for Continental Crust and then the $\mathrm{HH}, \mathrm{LH}, \mathrm{TH}$, $\mathrm{CN}, \mathrm{SH}$ and the lowest for Gangetic Plain.

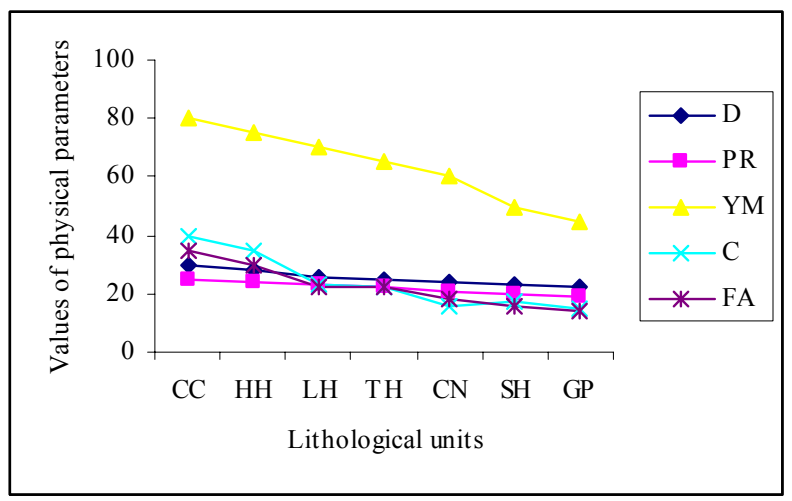

Fig. 4. Graphical presentation of physical parameter values of different layers of model. $\mathrm{D}=$ Density $\left(\mathrm{kg} / \mathrm{m}^{3}\right), \mathrm{PR}=$ Poisson's ratio, YM=Young's Modulus
(GPa), $\mathrm{C}=$ Cohesion $(\mathrm{MPa}), \mathrm{FA}=$ Angle of Internal Friction (degree), $\mathrm{TH}=$ Tethys Himalaya, $\mathrm{HH}=$ Higher Himalaya, $\mathrm{LH}=$ Lesser Himalaya, $\mathrm{SH}=$ Sub-Himalaya, $\mathrm{IC}=$ Continental Crust, $\mathrm{CN}=$ Chamba Nappe and GP = Modeling technique for predicting earthquakes

\section{Layer rheology}

The Himalayan profiles, which we used, consist of seven rock layers (Fig. 3). Continental crusts are considered to be composes of sandstone, gneiss and granite. The Higher Himalaya is composed of gneiss and schist which form the basement of the Tethys Himalaya with various kinds of leucogranite from Eocene to Middle Miocene and later (Searly et al. 1987). The age of Tethys Himalaya ranges from Cambrian to Tertiary period. Lesser Himalaya comprises relatively high-grade phyllite whose age is still controversial (Kaneko 1997; Upreti 1999). The Chamba Nappe is made of an approximately $10 \mathrm{~km}$ thick sequence of predominantly very low grade metasedimentary to sedimentary rocks underlain by the thrust wedge of the Lesser Himalayan Formations (Thakur et al. 2000). The Sub-Himalaya and Indian Gangetic Plain comprises of Neogene to Quaternary and recent fluvial sedimentary rocks (Kano 1984; Upreti 1999).

\section{Boundary condition}

Boundary conditions are derived primarily from the plate kinematics of the region. In order to mimic natural situation, we imposed displacement boundary conditions instead of forces because the velocity of plate movement between the Indian sub-plate and Eurasian plate is known. The boundary conditions are same for all experiments except for the value of displacement. The different convergent displacements, which are derived from the convergent velocities of Indian plate (2 $\mathrm{cm} / \mathrm{yr}$ ) multiplied by period, are imposed perpendicular to the right-side wall BC (Fig. 3). The left side edge AD is fixed horizontally. Node A is also fixed. The upper boundary CD is free, so as the earth's surface. As the value of displacement is given proportional to the distance from the point $\mathrm{A}$ along bottom line $\mathrm{AB}$, the imposed displacements are shown by arrows in Fig. 3. These imposed displacements are vectors which have both components of horizontal and vertical.

\section{Results and Discussion}

Role of layer rheology and boundary condition Simulations are performed with displacement boundary condition and rock layer properties which highlight the 
formation of faults in the Tethys Himalaya, Chamba Nappe, Lesser Himalaya, Sub-Himalaya and the Gangetic Plain. The faults within proposed model are determined considering the distribution of principal Howladar et al.

normal faults in the model, respectively. The faults are primarily influence by model parameters (boundary conditions and layer properties). With regards to the boundary condition, we examined a number of cases by imposing different convergent displacements. The representative models are shown in Fig. 5. During the experiments, we observed that the faults of all models are similar to each other, whereas with increasing convergence displacement, the failed area and the magnitude of principal stresses increase slightly which is clearly observed in the Tethys Himalaya, Chamba Nappe, Lesser Himalaya, Sub-Himalaya and the Gagetic Plain rock units (Fig. 5).

With respect to layers properties (density, Poisson's ratio, Young's modulus, cohesion and angle of internal friction), we have attempted to investigate the mode of failed elements for different layer properties in order to identify the suitable conditions that are likely to led to form the faults in the model. For this purpose, layer parameters of the model are varied one at a time, keeping others constant. It is observed that the cohesion and angle of internal friction are significantly effective in increasing the number of failed elements (faults) in the middle to upper region of the $\mathrm{TH}, \mathrm{CN}, \mathrm{LH}, \mathrm{SH}$ and the Gangetic Plain than the other properties. Thus the failed elements (faults) and magnitude of failed stresses are not only governed by the model boundary conditions but also by the applied values of different model's layer properties.

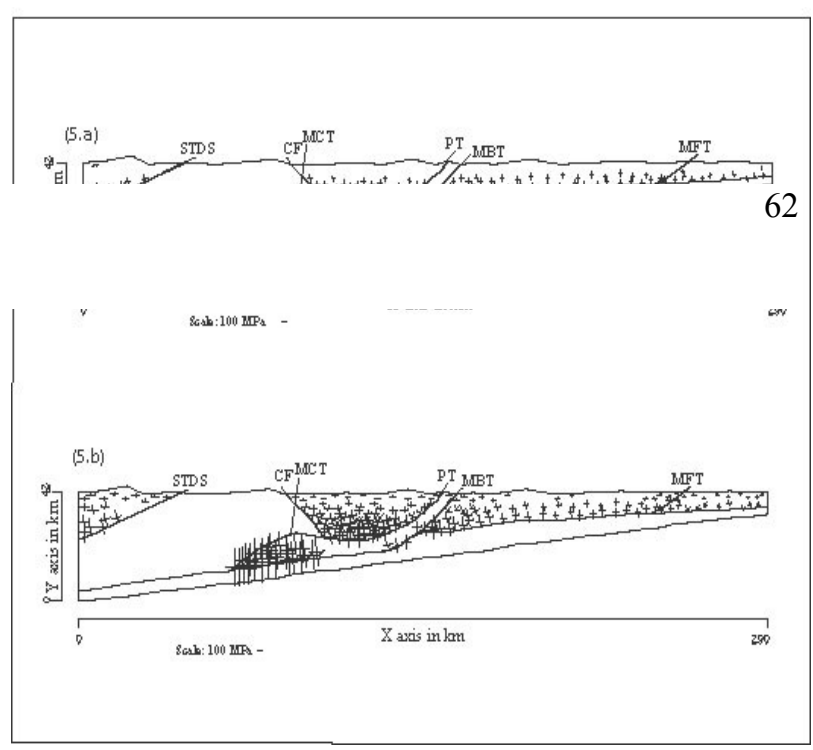

Fig. 5. Seismic faults of finite element elastic model $a$ and $b$ after applying the concept of proximity to failure with 200 and $400 \mathrm{~m}$ convergence displacement, respectively.

\section{Regional stress and fault pattern in the Himalayas}

Himalayas and neighbouring areas are the indicators of recent and sub-recent crustal movements due to the continental collision between the Indian and Eurasian plates. The relative motions between these plates influence the regional stress field and structures in the region. In recent years, the characteristics of regional stress have been interpreted by many authors (Molnar et al. 1977; Chandra 1978; Cloetingh and wortel 1986; Shanker et al. 2002; Howladar and Hayashi 2003, 2004). The direction of maximum horizontal shortening or horizontal compressive stress along the eastern Himalayan front is approximately N-S, parallel to the relative motions of these two plates (Nakata et al. 1990). However along the southern margin of the Eurasian plate, they are NE-SW in the western Himalayan front and NW-SE to E-W in the KirthernSulaiman front which are not consistent with the relative motions. He further noted that the direction of $\sigma_{\max }$ has changed following the change in direction of the relative motion between the Indian sub-plate and the tectonic sliver, which have detached together along the transcurrent faults in the Eurasian plates. These studies clearly indicate that the regional direction of maximum principal stress axis is consistent with the relative plate motions at least in the central part of Himalayan region. The stress state in the northern most part of Himalaya is quite different due to its different tectonic regime and structural configurations. Immediately north of the highest peak of the Himalayas, the tectonic regime is 
dominated by east-west extension, which is principally characterized by the strike-slip and normal fault system (Molnar et al. 1977; Blisniuk et al. 2001). The reasons of the extension in this region and its relationship to the change in elevation of Tibetan plateau are of the fundamental importance to the continental collision. The fault plane solutions of NW Himalayas (Fig.1 lower; Chandra 1978) indicate that the large numbers of thrust (dominantly), then normal and strike fault are under compressive stress regime.

Although the regional stress in the colliding boundary is generally considered to be dominated by the convergence of the Indian and Eurasian plates, the direction of the compressive stress axis is not consistent everywhere regionally in the region. The direction of compressive stress deduced from focal mechanism solution is at right angle to the topographical trend on all sides of the Indian Peninsula (Verma 1997). 63

Indian plate. Simulated models also show the compressive stress and faults in all stages of computation (Fig. 5), which is in good agreement with the local as well as regional compressive stress field and faults in the Himalayas.

\section{Prediction of Seismic Fault Zone (SFZ)}

Himalayan mountain range and its adjoining area is one of the most seismically active regions of the world. Nearly half of the Himalayan chain ruptured over the last century producing many earthquakes, among them, four earthquakes (magnitudes $>8$ ) were devastating which occurred in 1897, 1905, 1934 and 1989 (Molnar and Tapponnier 1975; Seebar et al. 1981; Ambraseys and Douglas 2004; Hua Wang et al. 2007). Most of the seismicity map (depth section; Fig. 6) shows the clustering of microseismic events (depth about 5-22 km) or epicenters along the foot-hill of the $\mathrm{HH}$. The detachment fault under the LH probably steeps and meets with the foot of the HH (Seebar et al. 1981; Bilham 2004). This structural geometry would be responsible for the existing ramp with south-northward dips in the LH (Schelling and Arita 1991). Steeping of the Moho inferred from gravity anomalies also shows the existence of this active ramp in this regime (Lyon-Caen and Molnar 1983). The geodetic and microseismic data over the last decade show strain and stress accumulation at the mid-crustal ramp. The mid-crustal ramp thus seems to behave as a geometric asperity during interseismic period (Pandey et al. 1995; Ambraseys and Jackson 2003). The seismic cycle along this part of the Himalayas thus probably involves interseismic period during which stress and strain build up at the crustal ramp, and the large seismic events that would release the elastically stored part of this deformation and allow transfer of the deformation ahead of the asperity. After initiation of deformation (faulting), probably in the vicinity of the ramp-flat transition, an event might evolve into a very large or medium size earthquake (Yats and Lilly 1991). Now, it is obvious that the most active seismic zone is along the foot-hill of $\mathrm{HH}$ where MCT, MBT, MHT, CN and MCR are very closely spaced with one another. In the present studies, we observed that the simulated normal (depth level $>15 \mathrm{~km}$ ) and thrust (depth level $>5 \mathrm{~km}$ ) faults are intensely localized along the Mid-lower part of $\mathrm{CN}$ and upper part of MCR. Thus, the distribution of simulated faults are well corresponded with the distribution of earthquakes epicenter or seismic events along these regimes of Himalayas. We, therefore, assume that the deeper part of nar 'Modeling technique for predicting earthquakes

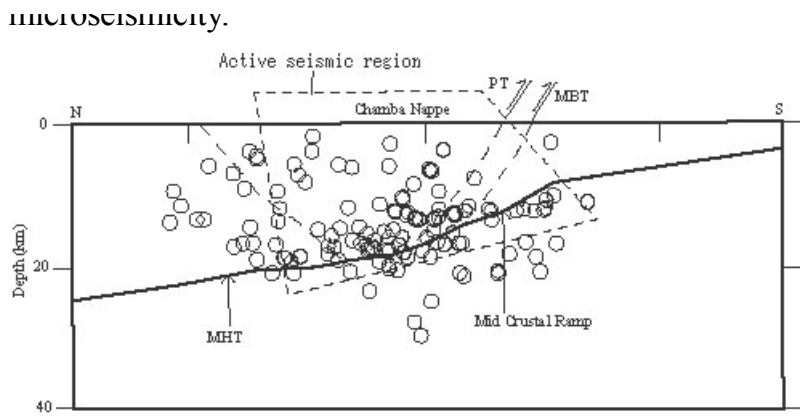

Fig. 6. Depth section of the distribution of earthquake foci across the NW Himalayan range (modified after Thakur 2000) showing the close similarity with the distribution of simulated faults.

\section{Neotectonic significance of the simulated faults}

The characteristics of Himalayan neotectonics are explained by Nakata (1989) based on the distribution of active faults and their relative tectonic features along the major thrusts (MCT, MBT and MFT) in the Himalayas. The Himalaya originated as a result of continent-continent collision between India and Asia. The northward convergence of India resulted in crustal shortening of the northern margin of the Indian continent, accommodated by south-verging thrusts (Upreti 1999). The principal thrusts, namely the MCT, the MBT and the MFT show younging age and shallowing depth, suggesting southward migration of the main deformation front. Neotectonic activity and active faulting related to the thrusts are observed on the surface in some restricted segments. The MCT remains largely inactive, except for in some reactivated segments, 
showing lateral strike-slip movement as in the central Nepal (Thakur 2004). The MBT in certain localized areas exhibits neotectonic activity. The MFT is the important tectonic features which existed along the frontal part of Himalaya. The Himalayan front is tectonically most active part of the Himalaya (Nakata 1990). Active faults are common features in the frontal zone, they appear mainly along the MFT. Thus, MFT shows wide active faulting area and associated uplift which represents a zone of active deformation between the $\mathrm{SH}$ and the Gangetic Plain. It demarcates the present day tectonic displacement zone between the stable Indian continent and the Himalaya with a convergence rate of $2 \mathrm{~cm} / \mathrm{yr}$ (Nakata 1989; Lave and Avouac 2000). From these features, it is clear that Himalayan present neotectonics is mainly due to a distribution of faults and active structures in the region. In the present analysis, we deduced the distribution of faults adopting numerical technique with present convergent rate of $2 \mathrm{~cm} / \mathrm{yr}$ (Lave and Avouac 2000), which shows close Howladar et al.

STDS in shallow depth as illustrated in Fig. 5. The existence of such faults along these major thrusts is in agreement with neotectonics in the Himalaya (Nakata et al. 1984). The model also shows that the frontal part of the Himalayas is more vulnerable to developing fault suggesting the active nature of the regime. This is consistent with the characteristics of neotectonics based on the active fault studies in the Himalayas. The Himalayan front is the most active fault zone of the Himalayas (Nakata 1989; Thakur et al. 2000). Thus, the simulated faults are the direct signatures of active structures and neotectonics of the present Himalayan collision.

\section{Conclusions}

A simple 2D plane strain finite element model has been presented to simulate the failure stress state and faults within the brittle upper crust of the earthquakes meizoseismal region of NW Himalaya. The results of the simulation are compared with the available seismic and earthquakes focal mechanism solution data of the region. The summary of the results is as follows:

1. Simulated failed state of stress is compressive in nature, where horizontal and vertical orientations are observed along the shallower and deeper area resulting in the thrust and normal faults of the model, respectively.

2. Structural style in the reentrants changes towards south. In the north, where detachment is deep and rock strength is great, the structures are fault propagation folds that have steep overturned limbs. In the south, where detachment is shallower and the rock strength is lesser, foreland strata gently deformed above the shallower dipping faults. The reentrants contrast with narrow parts of the Sub-Himalaya, where imbricate thrusting is common.

3. The thrust and normal faults are predicted in the $\mathrm{TH}$, $\mathrm{CN}, \mathrm{LH}, \mathrm{SH}$ and GP. All experiments predict faulting to initiate at depth and to transmit to shallower region with increasing convergent displacement, and finally propagate southward. This is consistent with the sequence of southward thrust development in the Himalayan orogenic belt.

4. The simulated compressive stress and faults are highly concentrated along where the MCR, MCT, MBT, $\mathrm{PT}$ and $\mathrm{CN}$ are closely spaced, being only few kilometers to few hundred meters apart, which corresponds the distribution of earthquakes epicenter in the area. This correlation suggests that the structural position of different fault/thrusts and the ramp behave as

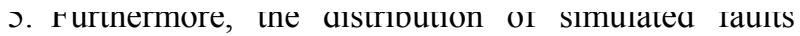
along the basal part of $\mathrm{SH}$ and $\mathrm{LH}$ indicates that this area coincides with the structural position of MHT which is connected with the flat detachment beneath the $\mathrm{LH}$ and the deep-seated deformation beneath the $\mathrm{HH}$.

Finally, combining and comparing all these data, we assume that the deeper part of $\mathrm{CN}$ and the region along the upper part of MCR in the LH may be the SFZ showing the high accumulation of simulated faults and the intense microseismicity. Moreover, the high concentration of faults in the southern part of model is associated with neotectonics of the regime.

Acknowledgements: We are thankful to Y. Sunagawa for helping to construct the primary model and to Prof. D. Hayashi, anonymous reviewers and Professor Dr. Mushfique Ahmed for their valuable comments, suggestions and necessary corrections which helped to improve the article to a great extent. We are also grateful to Harimoto N, Chief of Toyohanten Food Company, Naha, Okinawa, Japan for funding to this research work.

\section{References}

Anderson EM. 1951 ( $1^{\text {st }}$ edn $)$. The dynamics of faulting and dyke formation with applications to Britain. Edinburgh, $206 \mathrm{pp}$.

Ambraseys NN, Douglas J. 2004. Magnitude calibration of north Indian earthquakes. J Geophys J Int 158, 1-42.

Ambraseys N, Jackson D. 2003. A note on early earthquakes in northern India and southern Tibet. Current Sci 84(4), 
$571-582$.

Armbuster J, Seeber L, Jacob KH. 1978. The northwestern termination of the Himalayan mountain front: Active tectonics from microearthquakes. J Geophys Res 83, 269-282.

Bilham R. 2004. Earthquakes in India and the Himalaya: tectonics, geodesy and history, Annals Geophys 47(2), 839858.

Blisniuk P, Hacker BR, Glodny J, Ratschbacher J, Bi S, Wu Z, Mcwilliams MO, Calvert A. 2001. Normal faulting in central Tibet since at least $13.5 \mathrm{Ma}$ ago. Nature, 412, 628-632.

Chandra U. 1978. Seismicity, Earthquake Mechanisms and tectonics along the Himalayan mountain range and vicinity. Phys Earth Planet Inter 16, 109-131.

Cloetingh S, Wortel R. 1986. Stress in the Indo-Australian plate. Tectonophysics 132, 49-67.

DeCelles PG, Gehrels GE, Quade J, LaReau B, Spurlin M. 2000. Tectonic implications of U-Pb zircon ages of the

65

Howladar MF, Hayashi D. 2004. Simulation of Himalayan major thrusts by finite element method. J Geoinformatics 15(4), 207-219.

Howladar M F, Hayashi D. 2003. Numerical fault simulation in the Himalaya with 2D finite element method. J Polar Geoscience 16, 243-258.

Hua Wang, Linlin Ge, Caijun Xu, Zhixing. 2007. 3-D coseismic displacement field of the 2005 Kashmir earthquake inferred from satellite radar imagery. J Earth Planets Space 59(5), 343-349.

Jacob KH, Armbuster J, Seeber L, Pennington W. 1976. Tarbela reservoir:A region of compressional tectonics with reduced seism city upon initial reservoir filling. First Int. Symp. In induced seism city (ISIS), Banff, Canada, Engineering Geology.

Kaneko Y. 1997. Two-step exhumation model of the Himalayan metamorphic Belt, central Nepal. J Geol Soc Japan 103(3), 203-226.

Kano T. 1984. Geology and structure of the Main Central Thrust zone of the Annapurana range, Central Nepal Himalayas. J Geol Soc Japan 2, 31-50.

Lave J, Avouac JP. 2000. Active folding of fluvial terraces across the Siwaliks Hills, Himalayas of central Nepal. J Geophys Res 105, 5735-5770.

Lyon-Caen H, Molnar P. 1983. Constraints on the structure of the Himalaya from an analysis of gravity anomalies and a flexural model of the lithosphere. J Geophys Res $8 \mathrm{~B}(10)$, 8171-8191.

Molnar P, Tapponnier P. 1978. Active tectonics of Tibet. J Geophys Res 83, 5361-5375.

Molnar P, Fitch TJ, Wu FT, Chen WP, Warsi WEK,
Tapponnier P. 1977. Structure and tectonics of Himalaya: A brief summary of relevant geophysical observations of Himalaya. Science de la Terre, Center National de la Recherche Scientique, Paris. 11, 269-294.

Nakata T, Otsuki K, Khan S, M. 1990. Active faults, stress field and plate motion along the Indo-Eurasian plate boundary. Tectonophysics 181, 83-95.

Nakata T. 1989. Active faults of the Himalaya of India and Nepal. Special paper Geol Soc America 232, 243-264.

Nakata T, Iwata S, Yamanaka H, Yagi H, Maemoku H. 1984. Tectonic landforms of several active faults in the western Nepal Himalayas. J Nepal Geol Soc 4, 177-200.

Pandey MR, Tandukar RP, Avouac JP, Lave J, Massot JP. 1995. Interseismic strain accumulation on the Himalayan crustal ramp (Nepal). J Geophys Res Letter 22, 751-754.

Powers PM, Lillie RJ, Yeats RS. 1998. Structure and shortening of the Kangra and Dehra Dun reentrants, SubHimalaya, India. Bull Geol Soc America 110, 10101077

Modeling technique for predicting earthquakes

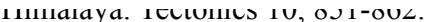

Seeber L, Armbruster JG, Quittmeyer RC. 1981. Seismicity and continental subduction in the Himalayan Arc. Geodynamic Series 3, 215-242.

Searle MP, Windley BF, Coward DJW, Rex AJ, Rex D, Tindong Li, Xuchang X, Jan MQ, Thakur VC, Kumar S. 1987. The closing of Tethys and the tectonics of the Himalaya. Geol Soc Bull America 98, 678-701.

Shanker D, Kapur N, Shing, B. 2002. Thrust-wedge mechanics and coeval development of normal and reverse faults in the Himalayas. J Geol Soc London 159, 273280.

Thakur VC. 2004. Active tectonics of Himalayan Frontal Thrust and Seismic Hazard to Ganga Plain. Current Sci 86, 1554-1560.

Thakur VC, Sriram V, Mundepi AK. 2000. Seismotectonics of the great 1905 Kangra earthquake meizoseismal region in Kangra-Chamba, NW Himalaya. Tectonophysics 326, 289-298.

Thakur VC. 1992. Geology of the Western Himalaya. Perga beneath the Himalaya. J Geophys Res 89, 1143-1147.

Upreti BN. 1999. An overview of the stratigraphy and tectonics of the Nepal Himalaya. J Asian Earth Sci 17, 577-606.

Verma RK. 1997. Paleomagnetism from Parts of Tethys Himalaya, Indus Suture Zone, Ladakh and South Tibet: Implications for Collision between Indian and Eurasian Plate. J Himalayan Geol 18, 93-102.

Yeats, Lillie. 1991. Contemporary tectonics of Himalayan frontal fault system: folds, blind thrust and the 1905 Kangra earthquake. J Structural Geology 13, 215-225. 
Zienkiewicz OC, Cheung K. 1967. The finite element method in structural and continuum mechanics. McGraw-Hill
Publishing Co. Ltd., England. 